\title{
A Comparison between Awareness and Observance of Patients' Rights Charter from the Perspectives of the Personnel, Students, and Patients in the Operating Rooms of the University Hospitals of Jahrom
}

\author{
Razieh Parniyan ${ }^{1}$, Zahra Pishgar ${ }^{2}$, Saiedeh Rahmanian ${ }^{2} \&$ Zahra Shadfard $^{2}$ \\ ${ }^{1}$ Department of Nursing, Faculty of Nursing and Midwifery, Jahrom University of Medical Sciences, Jahrom, \\ Iran \\ ${ }^{2}$ Department of Nursing, Jahrom University of Medical Sciences, Jahrom, Iran \\ Correspondence: Zahra Shadfard, Medical Surgical Nursing, Jahrom University of Medical Science, Motahari \\ St., Nursing \& Para-Medical School, Jahrom, Iran. Tel: 98-71-5434-1501. E-mail: Shadfard_OR@yahoo.com
}

Received: December 20, 2015 Accepted: March 7, 2016 Online Published: April 29, 2016

doi:10.5539/gjhs.v8n12p36

URL: http://dx.doi.org/10.5539/gjhs.v8n12p36

\begin{abstract}
Background and Objective: One of the most important issues in healthcare is an awareness of and adherence to patients' rights. Patients' physical, psychological, spiritual and social needs should be treated as if they are standards and regulations that medical teams should know about and observe. Considered as important worldwide, patients' rights are stressed in Islam too. The objective of the study is to compare the perspectives of the personnel, students, and patients in the university hospitals of Jahrom on care-providers' awareness of and observance of patients' rights in the operating rooms.
\end{abstract}

Method: The present study is a descriptive-analytical, cross-sectional project that conducted in 2014. The sample consisted of 478 subjects; the patients were sampled based on the stratified sampling method, while the operating room personnel and students were selected based on the census method. A researcher-designed questionnaire that ensured the validity and determined the reliability of it was used to collect data.

The collected data were analyzed using SPSS v. 23.

Result: The average awareness score of the personnel was found to be 19.54 with the standard devia3.25; their observance score was 17.75 with the standard deviation \pm 4.69 .

The average patient's-rights-awareness score of the patients was $15.99 \pm 5.82$, while their score for patient's rights observance was found to be $24.11 \pm 5.30$.

The average patient's-rights-awareness score of the students was $20.061 \pm 3.411$, while their score for patient's rights observance was found to be $18.892 \pm 6.271$.

The results of the study showed that the awareness level of both the students and personnel was higher than that of the patients. Also, a comparison between the perspectives of the three groups on observance of patients' rights revealed that the patients had higher expectations than both the students and personnel $(\mathrm{P} \leq 0.05)$.

Conclusion: These findings stress the need for raising patients' awareness about their rights and ways of demanding them in clinical environments. Raising students' awareness about patients' rights is equally important. Moreover, enhancing hospital personnel's familiarity with patients' rights can guarantee patients' health and satisfaction.

Patients' greater concern about adherence to patients' rights points to their rightful expectations and the need for hospital authorities and personnel to try harder to satisfy patients.

Respect for patients' basic rights and dignity is an important issue that is stressed by WHO too. As protectors of people's health and lives, healthcare providers play a crucial role in every society.

Keywords: patients' rights, awareness, observance, medical students, personnel, patients 


\section{Introduction}

Observance of patients' rights is an issue that is stressed in today's healthcare systems worldwide (Mahmoodi, 2012; Parsapour, 2007). An individual who visits a medical center due to a physical or psychological problem should not only be treated with respect, but his/her legal rights as a patient must be observed (Arab, 2009; Atashkhane, 2002; Sedghiyani, 1999). These rights include patients' legitimate physical, psychological, spiritual and social needs, all of which are considered in medical regulations which must be followed by all the members of medical teams. In other words, they are part of the responsibilities that a medical center has for its patients (Abedian, 2015; Anonymous, 2008; Easley \& Allen, 2007; Voskouiy, 2010; Woogara, 2005). The topic of patients' rights has become increasingly important in many countries over the past decade (Nikbakht, 2006); a review of the history of patients' rights in the world will verify the claim (Mahmoodi, 2012). In many valid Islamic documents, too, observance of patients' rights and providing patients with the best possible care are frequently stressed and a great divine reward is promised for such behavior (Javadiamoli, 2013).

In Iran, the patients' rights charter was enacted in 2002, when the Ministry of Health, Medical Treatment, and Education began to adopt a new and more comprehensive perspective on both the rights of the individuals who sought medical care and the observance of professional ethics in medical professions (Parsapour, 2000). The objective of the patients' rights charter is to protect patients' rights and dignity as human beings irrespective of race, age, gender, and financial status. In the patients' rights charter, it is stated that patients are entitled to private care, receiving precise information about their diagnosis, treatment, and prognosis, and making decisions about their treatment plans; yet, generally, a patient's treatment plan is considered confidential (Sedghiyani, 1999; Rangrazjedi, 2003).

Studies show that patients who are aware of their rights are better at making decisions about their treatment plans than others, which in turn expedites their recovery process and decreases their lengths of hospital stay. Therefore, all the individuals who are involved in caring for patients should respect their rights, be adequately aware of the related regulations, and make an effort to fulfill their patients' expectations and provide them with quality care while treating them with respect (Arab, 2009; Asasi, 1998). If a medical team is not aware of patients' rights, it cannot observe those rights, which will result in a slower recovery process for patients, longer hospital stays, patients' irritability and dissatisfaction, and higher treatment costs (Kelrozi, 2001; Rahimikiyan, 2008).

According to some Conducted studies in theWorld, the most patients are not aware of their rights and nurses' awareness and Observance of patient's rights in various hospitals is in moderate level and varies from $30 \%$ to 60\% (Abedian, 2015; Ducinskiene,Vladickiene, Kalediene, \& Haapala, 2006; Heidari, Ahmadpour, \& GharehBoughlou, 2013; Iltanen, Kilpi, Puukka, \& Suhonen, 2012; Kumar, Mehta, \& Kalra, 2011; Mohammadnejad, Ehsani, Beigjani, Aboutalebi, \& Kalantarzadeh, 2012; Nejad, Begjani, Abotalebi, Salari, \& Ehsani, 2011).

In their study, Arab and Zareie discovered that only $23 \%$ of the medical administrators in the hospitals they had selected for study were satisfactorily aware of patients' rights (Arab, 2009). On the other hand, Voskouiy et al. found that $53.2 \%$ of the patients in the hospitals affiliated with Tehran University of Medical Sciences were satisfied with the care-providers' observance of patients' rights; the patients were found to be most satisfied with the observance of their right to know and least satisfied with the observance of their right to independence and decision-making (Voskouiy, 2010). Yaghoubi's study of intern medical and nursing students' awareness of the regulations related to patients' rights shows that $64 \%$ of the subjects approved of the patients' right to have access to their medical records (Yaghoubi, 2003).

In their comparison of the perspectives of patients, doctors, and nurses on observance of the regulations in the patients' rights charter, Parsapour et al. found that the entire study groups agreed that there was need for a more careful observance of patients' rights. They also found that the most disagreement among the study groups was over patients' rights to know, choose, and make decisions; accordingly, it seems necessary that care-providers, especially medical teams, should be made aware of patients' rights to know, choose, and make decisions - it appears that patients' expectations concerning their rights are higher than what the members of medical teams assume (Parsapour, 2007).

The results of the study of Shiraz et al. show that intern and surgery students' knowledge of medical ethics is very poor (Shiraz, Shamim, \& Ahmed, 2005).

Also, according to Nasirian et al., nurses believe that in more than $50 \%$ of cases, observance of patients' rights is average (Nasiriani, 2007). Similarly, Rangraze jedi (2003), Ghasemi (2003), and Voskouiy (2010) report that in their studies, patients' rights are not fully observed from the patients' perspective. 
A review of the available literature on patients' rights revealed that there were no studies on observance of patients' rights in operating rooms. In operating rooms, where patients have to go through various procedures, among them receiving local and general anesthetics, it is mandatory that the personnel be aware of and fully observe their patients' rights; moreover, patients' awareness of their own rights can enhance their abilities to make decisions and deal with their diseases. Since every clause in the Iranian patients' rights charter is based on our religious beliefs and national values, it is important that we identify the barriers to and strategies for implementing the charter. Accordingly, the present study aims to determine and compare the current level of awareness and observance of patients' rights from the perspectives of the personnel, students, and patients in the operating rooms of the university hospitals of Jahrom.

\section{Materials and Method}

\subsection{Study Population, Sample, and Sampling Method}

The present study is a descriptive-analytical, cross-sectional project which aims to determine and compare the current level of awareness and observance of patients' rights from the perspectives of the personnel, students, and patients in operating rooms. Based on a review of the available literature on awareness and observance of patients' rights charter, sample size was set at 478 subjects. The surgery wards and operating rooms of Mottahari Hospital and Peymanieh Hospital in Jahrom formed the research environment.

The inclusion criteria for the patients were having undergone surgery in an operating room, being aged over 15 years, and having the ability to participate in the study. All the operating room personnel and the operating room and anesthesiology students present in the operating rooms of the above-mentioned hospitals were included in the study. Patients who were under 15 years, did not have the physical or mental conditions for participation, or were not willing to participate were excluded.

\subsection{Study Instruments}

A researcher-designed questionnaire was used to collect data; The questionnaire was developed in three parts: demographics, awareness of patients' rights charter (6 items), and observance of patients' rights charter (9 items) from the perspectives of the patients, personnel, and students in the operating rooms. The items were scored based on a 5-point Likert scale, ranging from 0 to 4 , and the score results were reported as averages.

The questionnaire was completed by the researchers based on the patients' answers. On the other hand, the questionnaire the personnel and students were asked to complete was of the self-completion type

To ensure the validity of the questionnaire, the researchers did a comprehensive review of the available literature, including the Patients' Rights Charter as enacted by the Ministry of Health, Medical Treatment, and Education, and consulted the faculty members of Jahrom University of Medical sciences.

To determine the reliability of the questionnaire, the researchers used the pretest-posttest method: the researchers had 20 individuals complete the questionnaire and found the Cronbach's alpha for awareness and observance to be 0.7 and 0.83 respectively.

\subsection{Data Analysis}

Collected data were analyzed using descriptive and inferential statistics on SPSS (statistical pakage for the social science, version 21, Inc., Chicago, IL, USA). Using descriptive statistics, standard deviations and frequencies, OneSample kolmogorov-SmirnovTest, Mann-Whitney Test, Anova, and TukeyHSD.

\section{Intervention}

After the research proposal had been approved by the Research Committee of Jahrom University of Medical Sciences, The patients were sampled based on the stratified sampling method (and systematically in each stratum), while the operating room personnel and students were selected based on the census method.They were assured that their responses would remain confidential, and that their names were not required. The researchers observed the ethical considerations. Overall, the distribution and collection of the questionnaires took in 12 month.

\section{Result}

The total number of the personnel surveyed was $44,77.3 \%$ of whom were female and $22.7 \%$ were male; in terms of education level, $4.5 \%$ had a high-school diploma, $38.6 \%$ had a post high-school diploma, $54.5 \%$ had a bachelor's degree, and $2.3 \%$ had a Ph.D. in either anesthesiology or operating room studies. Also, $43.2 \%$ of the personnel had a professional experience of 1-5 years and 3\% had a professional experience of 16-20 years.

The average awareness score of the personnel was found to be 19.54 with the standard deviation of \pm 3.25 ; their 
observance score was 17.75 with the standard deviation \pm 4.69 .

The total number of the patients surveyed was $472,47.5 \%$ of whom were female and $52.5 \%$ were male; in terms of education level, $34.7 \%$ were uneducated, $29.9 \%$ had a junior high-school diploma, $21.8 \%$ had a high-school diploma, and $13.3 \%$ had a college degree. In terms of occupation, $5.7 \%$ were governmental employees, $39.8 \%$ were self-employed, $42.4 \%$ were housewives, $5.3 \%$ were unemployed, and $6.8 \%$ were college students. $52.1 \%$ of the patients were city dwellers and $41.9 \%$ were residing in villages. The average length of hospital stay was found to be $2.94 \pm 3.34$ days.

The average patient's-rights-awareness score of the patients was $15.99 \pm 5.82$, while their score for patient's rights observance was found to be $24.11 \pm 5.30$.

The result of the Mann-Whitney test shows that there is a significant difference between the levels of awareness and observance of patients' rights from the personnel's perspective based on their gender $(\mathrm{P}<0.05)$ (Table 1).

The total number of the students surveyed was $130,68.5 \%$ of whom were female and $31.5 \%$ were male; their average age was found to be $21 \pm 1.93$. The students' majors were either anesthesiology or operating room monitoring. The results showed that $63.1 \%$ were aware of patients' rights and their main source of information in this regard was their teachers (49.2\%).

The average patient's-rights-awareness score of the students was $20.061 \pm 3.411$, while their score for patient's rights observance was found to be $18.892 \pm 6.271$.

The result of the Mann-Whitney test shows that there is a significant difference between the levels of awareness and observance of patients' rights from the students' perspective based on their gender $(\mathrm{P} \leq 0.05)$.

Also, based on the Mann-Whitney test, there is not a significant difference between the levels of awareness and observance of patients' rights from the students' perspective based on their majors ( $\mathrm{P} \geq 0.05)$ (Table 2).

The results showed that there was a significant difference between the levels of awareness and observance of patients' rights from the perspectives of the three groups. The results of one-way analysis of variance show that there is a difference between the perspectives of the three study groups (patients, students, personnel) on both awareness and observance of patients' rights $(\mathrm{P}<0.05)$ (Table 3$)$.

Moreover, the results of the study showed that the awareness level of both the students and personnel was higher than that of the patients. Also, a comparison between the perspectives of the three groups on observance of patients' rights revealed that the patients had higher expectations than both the students and personnel $(\mathrm{P} \leq 0.05)$. The results of Tukey's range test show that there is a significant difference between the students and patients in terms of awareness: the students' awareness is higher than the patients' $(\mathrm{P} \leq 0.05)$.

Also, the results of Tukey's range test show that there is a significant difference between the personnel and patients in terms of awareness: the personnel's awareness is higher than the patients' $(\mathrm{P} \leq 0.05)$.

The results of Tukey's range test show that there is a significant difference between the students' and patients' perspectives on observance of patients' rights: the patients' expectations were higher than the students' $(\mathrm{P} \leq 0.05)$.

The results of Tukey's range test also show that there is a significant difference between the personnel's and patients' perspectives on observance of patients' rights: the patients' expectations were higher than the personnel's $(\mathrm{P} \leq 0.05)$ (Table 4).

Table 1. The average awareness and observance of patients' rights from the personnel's perspective based on their gender

\begin{tabular}{lllll}
\hline & Sex & Mean Rank & z & P.value \\
\hline \multirow{2}{*}{ Awareness } & Women & 262.63 & -4.230 & $\leq 0.05$ \\
\multirow{2}{*}{ Observance } & Men & 209.47 & & \\
& Women & 262.57 & -5.061 & $\leq 0.05$ \\
\hline
\end{tabular}


Table 2. The levels of awareness and observance patients' rights from the students' perspective based on their gender and their majors

\begin{tabular}{llllll}
\hline & Sex & Mean Rank & Mean \pm SD & P.value & Z \\
\hline \multirow{2}{*}{ Awareness } & Women & $\mathbf{8 6 . 6 8}$ & $\mathbf{2 0 . 2 7} \pm \mathbf{3 . 5 3}$ & $\mathbf{0 . 1 3 1}$ & $\mathbf{- 1 . 1 5 1}$ \\
& Men & $\mathbf{5 8 . 2 1}$ & $\mathbf{1 9 . 6} \pm \mathbf{3 . 1 2}$ & & \\
& Women & $\mathbf{6 0 . 7 9}$ & $\mathbf{1 8 . 1 2} \pm \mathbf{6 . 2 4}$ & $\mathbf{0 . 0 3 5}$ & $\mathbf{- 2 . 1 0 3}$ \\
& Men & 75.72 & $\mathbf{2 0 . 5 6} \pm \mathbf{6 . 0 9}$ & & \\
\multirow{2}{*}{ Awareness } & Field of Study & & & & \\
& Anesthesiology & 68.24 & $\mathbf{2 0 . 1 6} \pm \mathbf{3 . 6 1}$ & $\mathbf{0 . 3 4 4}$ & $\mathbf{- 0 . 9 6 4}$ \\
& operating room & 61.99 & $\mathbf{1 9 . 9 3} \pm \mathbf{3 . 1 7}$ & & \\
& Anesthesiology & 67.89 & $\mathbf{1 9 . 4 7} \pm \mathbf{6 . 8 3}$ & $\mathbf{0 . 4 1 2}$ & $\mathbf{- 0 . 8 2 0}$ \\
\hline
\end{tabular}

Table 3. Levels of awareness and observance of patients' rights from the perspectives of the three groups

\begin{tabular}{lllll}
\hline Variable & & Mean \pm SD & f & P.value \\
\hline \multirow{3}{*}{ Awareness } & students & $20.061 \pm 3.411$ & & \\
& Personnel & $19.545 \pm 3.252$ & $\mathbf{3 5 . 5 8}$ & $\mathbf{0 . 0 0 0}$ \\
& patients & $15.989 \pm 5.820$ & & \\
Observance & students & $18.892 \pm 6.271$ & $\mathbf{6 4 . 4 6}$ & $\mathbf{0 . 0 0 0}$ \\
& Personnel & $17.750 \pm 4.695$ & & \\
\hline
\end{tabular}

Table 4. Difference between levels of awareness and observance of patients' rights from the perspectives of the three groups

\begin{tabular}{|c|c|c|c|c|c|}
\hline & & students & & patients & \\
\hline Variable & & Mean \pm SD & P.value & Mean \pm SD & P.value \\
\hline \multirow{3}{*}{ Awareness } & students & & \multirow{3}{*}{0.000} & & \multirow{3}{*}{0.000} \\
\hline & Personnel & & & $-3.556 \pm 0.832$ & \\
\hline & patients & $4.072 \pm 0.523$ & & & \\
\hline \multirow[b]{2}{*}{ Observance } & students & & \multirow[b]{2}{*}{0.000} & & \multirow[b]{2}{*}{0.000} \\
\hline & $\begin{array}{l}\text { Personnel } \\
\text { patients }\end{array}$ & $-5.221 \pm 0.544$ & & $6.363 \pm 0.865$ & \\
\hline
\end{tabular}

\section{Discussion}

According to the results of the study, the personnel believed that awareness of patients' rights is greater than observance of patients' rights; also, no correlation was found between the personnel's awareness of patients' rights and their gender, education level, professional experience or major.

In other words, despite the fact that personnel's awareness level correlates positively with their education level and professional experience, the personnel believed that patients' rights were less carefully observed by medical personnel in the operating rooms. In Kelrozi's study, the patients were found to be more satisfied with the doctors' observance of the patients' rights charter than the nurses' observance of the charter: the patients' dissatisfaction with the nurses' performance in this regard was twice as much as their dissatisfaction with the doctors' performance (Kelrozi, 2001). However, Nasirani et al. report that, from the nurses' perspective, observance of patients' rights is in more than $50 \%$ of cases at an average level (Mahmoodi, 2012; Nasiriani, 2007).

On the other hand, Shiraz's study in Pakistan shows that surgery team members have a poor awareness of patients' rights and medical ethics (Shiraz, Shamim, \& Ahmed, 2005).

While Mosaddeghrad's study in Isfahan shows that the patients'-rights awareness of the medical personnel is 
excellent (Basiri, 2012; Rad \& AsnaAshari, 2004), Zareie reports that only 23\% of the managers of the private hospitals in Tehran are satisfactorily aware of patients' rights (Basiri, 2012; Zarei, Arab, \& Akbari, 2007). Krzych report that, to treatment (50.5\%), and the doctors' right to refuse the presence of a person close to the patient during treatment $(16.4 \%)$ while over $80 \%$ respondents were aware of their rights such as: choose a treating physician, refusal of the proposed treatment, the choice of the place (Krzych, 2013).

In his study, Houshmand states that an awareness of patients' rights does not necessarily result in observance of those rights by medical staff: the results of many studies and observations in hospitals prove that patients' rights are ignored in many cases; to eliminate this problem, it is necessary that people, care-providers and policy-makers all collaborate with each other (Houshmand, 2007; Joolaees, Nasrabadi, Yaktaz, Tschudin, \& Mansouri, 2006). Similarly, Ledo et al. report that though $84 \%$ of the nurses in their study were aware of patients' rights, only $65 \%$ observed them during their daily activities at work (Ledo, Salas, \& Gonzalez, 1998). Likewise, the results of Nasiriani's study in Yazd show that despite having a satisfactory awareness of patients' rights (57\%), few nurses (9\%) observe these rights in practice (Nasiriani, 2007).

It is important that care-providers make an effective effort to learn the content of the patients' rights charter: to use their knowledge effectively, care-providers need to be aware of the rules and regulations that govern relationships among individuals (Bateni, 2013); however, it is also important that health and medical centers provide proper education and identify and eliminate the barriers to ensure complete fulfillment of the guidelines presented in the charter. Studies show that care-providers' observance of the charter facilitates patients' recovery, increases their satisfaction, and reduces the incidence of side-effects and length of stay; on the other hand, care-providers who are not aware of patients' rights cannot handle the challenges on the way (Rahimikiyan, 2008). In the present study, women's average awareness scores were found to be higher than their average observance scores. Similarly, from the male participants' perspective, the level of observance was lower than the level of awareness.

In their respective studies, Rangraz, Ghasemi, and Voskouiy and Ashkouiy conclude that most patients believe that their rights are not properly observed (Mahmoodi, 2012; Voskouiy, 2010; Rangrazjedi, 2003; Ghasemi, 2003).

Mosaddeghrad's study in Isfahan shows that patients' awareness is poor. In the present study, observance of patients' rights from the patients' perspective was found to be $24.11 \pm 5.3$; however, Babamahmoudi's study in Mazandaran reports a $14.59 \%$, Rangraz's study in Kashan reports a $67.74 \%$, and Voskouiy and Ashkouiy's study reports a $53.2 \%$ patients' satisfaction with observance of their rights. In China, only $9.5 \%$ of medical staff thought that patient treatment would be compromised by refusal to participate (Liang, 2012). In Turkey, only 9\% of patients were reported to be aware of their rights (Kuzu, 2006). In Poland, patients had the least awareness about the form of giving consent (42.9\%) or refusal consent (Krzych, 2013).

Since the results show that the patients' awareness of patients' rights is low, it seems necessary that patients should be educated on what they are entitled to; this will raise their expectations, which will in turn lead to care-providers' observing the patients' rights charter, the provision of better quality care, and facilitation of patients' recovery process. On the other hand, a poor awareness will make patients have low expectations about their rights and the services they receive, which will in turn make care-providers reluctant to improve their work and be dynamic in medical centers.

In general, considering the expansion of social relationships, people need to know their rights and learn the regulations that are related to them more than ever (Bateni, 2013). The WHO Regional Office for Europe describes the fulfillment of patients' rights as a multi-faceted issue that everyone is responsible for. The strategies suggested by WHO for encouraging respect for patients' rights include the active participations of the receivers and providers of medical care in medical policy-making procedures and the expansion of educational programs to include not only the care-providers but the whole members of the society (Joint, 1999; Houshmand, 2007).

The results of the present study show that $63.1 \%$ of the students were aware of patients' rights and that there was a difference between the female and male students' level of awareness as there was a difference between their attitudes toward observance of patients' rights: although the female students' awareness was higher than the male students', their performance was poorer, which difference can be attributed to the male students' greater courage for work in clinical environments, greater physical strength, or higher motivation (e.g. financial reasons) for participation in social activities.

The students' average awareness score was $20.06 \pm 3.41$, while their average observance score was found to be $18.89 \pm 6.27$. The students' higher awareness scores can be attributed to their not having had any practical 
experience alongside their theory courses or their low self-confidence or sense of responsibility. In Khodamoradi's study, the average awareness score of undergraduate and postgraduate nursing students is reported to be $13.68 \pm 3.21$; the researcher also reports that $68.4 \%$ of the students were satisfactorily aware of the patients' right to having access to medical services (Khodamoradi, 2014). However, in the study of Ranjbar et al., only $23 \%$ of the students had a satisfactory awareness of patients' rights in this area; also, $35.6 \%$ of the students had a poor, $27.7 \%$ had a moderate, and $36.7 \%$ had a satisfactory awareness of the patients' rights charter (Ranjbar, 2008). On the other hand, in Yaghoubi's study, the majority of the medical and nursing students are reported to be sufficiently aware of patients' rights (Yaghoubi, 2003).

In the study of Khodamoradi et al., $71.5 \%$ of the students had a sufficient awareness of a patient's right to accept or refuse treatment, while in Ranjbar's study, $46.8 \%$ of the students were found to have such awareness to a satisfactory extent. Also, regarding the confidentiality of a patient's information, $69.8 \%$ of the students in Khodamoradi's study and $32.7 \%$ in Ranjbar's study had a satisfactory awareness of this right of patients.

Since during their clinical training, students are in direct contact with patients, they need to be aware of and observe patients' rights like the other members of medical teams. Yet, since students' participation in treatment plans may not directly benefit patients or may even cause problems for them, some people question such participation for ethical reasons; students also need to learn to respect patients and keep their information confidential (Ranjbar, 2008; Larijani, 2006).

An analysis of the differences between the study groups revealed that the patients had a lower level of awareness than did the students, which stresses the need for educating patients and raising their awareness of their rights, which will in turn improve the quality of services offered to patients in health and medical centers.

At the same time, it is important that steps be taken to enhance students' awareness too: by motivating their students and stressing practical skills in clinical education, educators can encourage students to absorb and apply knowledge about patients' rights.

In addition, the medical personnel's higher awareness of patients' rights compared to the patients is promising; however, it is suggested that health and medical authorities plan and implement programs to reinforce this knowledge, which will in turn guarantee patients' recovery and satisfaction.

The fact that the patients attached greater importance to observance of patients' rights compared to the students and personnel shows that patients rightfully expect that their rights should be respected. Accordingly, it is important that medical authorities and personnel try harder to satisfy patients.

\section{Conclusion}

In Iran, the rich culture and the religious instructions have always stressed the importance of respecting humans' rights, patients' rights included. The necessity of respecting patients' basic rights and dignity is reinforced by their vulnerability to the weaknesses in health and medical systems (Barnett, 2008). According to WHO, all the members of medical teams should collaborate to create the conditions required for respecting patients' rights (Anonymous, 1999). In the domain of health and medical treatment, where protecting people's health and lives is the primary goal of the individuals who work in this field, observing patients' rights is especially important (Ranjbar, 2008; Abraham, 2005).

\section{Competing Interests Statement}

The authors declare that there is no conflict of interests regarding the publication of this paper.

\section{References}

Abedian, K., Nesami, M. B., \& Shahhosseini, Z. (2015). The Effect of an Education-Based Intervention on Self-ReportedAwareness and Practice of Iranian Nurses in Observing Patients' Rights. Global Journal of Health Science, 7(3).

Abraham, A. (2005). National Symposium on Patient Bill of Rights. Fasa. Iran University of Medical Science, $22-21$.

Anonymous. (1999). WHO, patients'rights and citizens'Empowerment. Therough visions to Reality.

Anonymous. (2008). Patient's rights in new yourk. Retrieved from http://state.www.healthstate.ny.us

Arab, M. (2009). Management nomination about patient's right in private hospitals in Tehran. Payesh Journal, 1(87), 25-30.

Atashkhane, M. (2002). First publish, shiraz, treatment assistant Fars province. 
Barnett, A. (2008). An assessment of the process of informed consent at the university hospital of thewest Indies. J Med Ethics, 34, 344-347. http://dx.doi.org/10.1136/jme.2007.020388

Basiri, K. M. (2012). Knowledge of patients and health providers of patient rights and observance of the one of the teaching hospitals. OfoghDanesh. Journal of Gonabad University of Medical Sciences, 17(1), 54-45.

Bateni, M. (2013). Patient's knowledge about their rights. Management of Health Information, 7(4), 485-489.

Ducinskiene, D., Vladickiene, J., Kalediene, R., \& Haapala, I. (2006). Awareness and practice of patient's rights law in Lithuania. BMC International Health and Human Rights, 6(1), 10. http://dx.doi.org/10.1186/1472 $-698 \mathrm{X}-6-10$

Easley, C. E., \& Allen, C. E. (2007). A critical intersection: Human rights, public health nursing, and nursing ethics. Advances in Nursing Science, 30(4), 367-382. http://dx.doi.org/10.1097/01.ANS.0000300185. 94595.6c

Ghasemi, M. (2003). Assessment of patients' rights respecting the territory and hospitalized patients of Sabzevar. National Symposium on Patient Bill of Rights. IRAN, Fasa University of Medical Sciences.

Heidari, A., Ahmadpour, Z., \& GharehBoughlou, Z. (2013). Patients and nurses awareness of patient's rights: A comparative study. Health, Spirituality and Medical Ethics, 1(1).

Houshmand, A. (2007). Knowledge of nurses working in hospitals in patient rights in Tehran and facilitating factors for the observance of these rights in their view. The Faculty of Nursing and Midwifery. Tehran University of Medical Sciences, 12(4), 66-57.

Iltanen, S., Leino Kilpi, H., Puukka, P., \& Suhonen, R. (2012). Knowledge about patients' rights among professionals in public health care in Finland. Scandinavian Journal of Caring Sciences, 26(3), 436-448. http://dx.doi.org/10.1111/j.1471-6712.2011.00945.x

Javadiamoli, A. (2013). Meftaholhayat.ghom. Asra, 361-368.

Joint Consultation Between the who Regional office for Europe. The Nordic council of Ministers and the Nordic school of Public Health. (1999). Patients' rights and citizens' empowerment: Through visions of reality. Copenhagen. Denmark.

Joolaees, N., Nasrabadi, A. R., Parsa, Y., Tschudin, V., \& Mansouri, I. (2006). An Iranian perspective on patients' rights: Experiences of patients and their companion. Nursing Ethics, 13(5), 488-502. http://dx.doi.org /10.1191/0969733006nej895oa

Kelrozi, F. (2001). The patient's satisfaction in esteeming patient's right. Army Medicine, 12, 143-148.

Khodamoradi, K. (2014). The survey of MA and BA students of nursing about patient's right. Medical Law Quarterly, 50(17), 177-183.

Kumar, R., Mehta, S., \& Kalra, R. (2011). Knowledge of staff nurses regarding legal and ethical responsibilities in the field of psychiatric nursing. Nursing and Midwifery Research, 7(1), 1-11.

Larijani, B. (2006). Ethical considerations in clinical education of medical. Iranian Journal of Diabetes and Lipid, 1385(Especially a Clinical Research Ethics)(4), 9-105.

Ledo, R., Salas, L., \& Gonzalez, E. (1998). The rights of the hospital Patient: The know ledge and perception of their fulfilment on the part of the professional. The Group in Catalonia of the Spanish society of care for the Health services user. Rev Clin Esp, 198(11), 730-5.

Mahmoodi, B. (2012) .The survey of esteeming patient's right in Mazandaran educational hospital in view of patients. Journal of Medical History and Ethic, 4(4), 37-43.

Mohammadi, J. (1998). Assess knowledge and attitude to the legal rights of the patient and the nurse. The nurse and the Law Conference. Tehran.

Mohammadnejad, E., Ehsani, S. R., Beigjani, J., Aboutalebi, G., \& Kalantarzadeh, M. (2012). Exploring the extent of the Nurses' Awareness of the Patients' Rights in an Educational Hospital in 2010. Medical Ethics, 1(19), 68-84

Moshegh Rad, A. M., \& AsnaAshari, P. (2004). Physicians and Patients' awareness of patients' rights and its observation in shahidBeheshti hospital. Journal of Education in Medical Sciences, 45-53.

Nasiriani, G. H. (2007). Evaluate patient rights of nurses in the hospitals of Yazd. Journal of Forensic Medicine, 13(1), 7-33. 
Nejad, E. M., Begjani, J., Abotalebi, G., Salari, A., \& Ehsani, S. R. (2011). Nurses' awareness of patients rights I a teaching hospital. Journal of Medical Ethics and History of Medicine, 4(2)

Nikbakht, A. (2006). Patient's Right Nomination in Sight of thier entourages, the summary of law regional congress. Law and professional responnsibilty in Islamic Azad university of Kraj.

Parsapour, A. (2000). Patients' right in Iran. Journal of Medical History and Ethic, 39-47.

Parsapour, A. (2007). Survey of patients, doctors, nurses' viewpoint, specific educational-remedial hospitals, first class hospital in esteeming patient's right. Journal of Medical History and Ethics, 4(8), 79-89.

Rahimikiyan, F. (2008). Importance of professional ethics in medical science. Tehran University of medical science.

Rangrazjedi, F. (2003). The survey of esteeming in Kashan national hospital. Behboud Journal, 9(1), 61-72.

Ranjbar, M. (2008) Knowledge of students' clinical training in teaching hospitals of Yazd in 1388 on patient rights patient. Especially the Journal of Medical Ethics and History, (3), 60-51.

Razavi, N. (1999). Determine the knowledge of medical and nursing staff and patients. Conference management role in health care, Kerman.

Sedghiyani, E. (1999). Organization and hospital management. Tehran. World Computer, 1, 117-483.

Shiraz, B., Shamim, M. S., \& Ahmed, A. (2005). Medical ethics in surgical wards: Knowledge, attitude and practice of surgical team members in Karachi. Indian J med Ethics, 2(3), 94-6.

Voskouiy, K. H. (2010). The survey of esteeming patient's right in Tehran vassal educational hospital. Journal of Medical History and Ethic, 2(4), 47-53.

Woogara, J. (2005). Patients' rights to privacy and dignity in the NHS. Nursing Standard, 19(18), 33-37. http://dx.doi.org/10.7748/ns2005.01.19.18.33.c3783

Yaghoubi, T. (2003). Comparative study of patient rights in selected countries. National Symposium on patient rights and health care. Fasa University of Medical Sciences.

Zarei, A., Arab, M., \& Akbari, F. (2007). Managers' knowledge on patient rights in Tehran hospitals. The Journal of Qazvin University of Medicalscience, 11(3), 65-71.

\section{Copyrights}

Copyright for this article is retained by the author(s), with first publication rights granted to the journal.

This is an open-access article distributed under the terms and conditions of the Creative Commons Attribution license (http://creativecommons.org/licenses/by/3.0/). 